\title{
DESCRIPCIÓN DE PATRONES NORMALES Y ANORMALES DE PLÁNTULAS DE Juglans nigra
}

\author{
Flores, P. ${ }^{1} ;$ PogGI, D. ${ }^{1} ;$ Garcia, S. ${ }^{1}$; \\ Catraro, M. $^{1}$ \& Gariglio, N. ${ }^{2}$
}

\begin{abstract}
RESUMEN
Juglans nigra en una especie de relevancia económica y con un elevado nivel industrial y tecnológico cultivándose por su madera, como portainjerto del nogal europeo, y por sus frutos para la alimentación humana. En la Prueba de Germinación Estándar, y en diferentes pruebas para determinar el vigor de las semillas los resultados se expresan en Porcentaje de Plántulas Normales. El objetivo de este trabajo fue describir patrones de plántulas normales y anormales de J. nigra como herramientas para ser utilizadas en todas aquellas pruebas que expresan sus resultados en porcentaje de plántulas normales. Se describieron las categorías: Normales Vigorosas (plántulas libres de lesiones), Normales Débiles (plántulas con deficiencias o lesiones leves) y Anormales con defectos a nivel de raíz y epicótile.

Palabras clave: Juglans nigra, plántulas normales, plántulas anormales.
\end{abstract}

\begin{abstract}
Description of normal and abnormal seedlings patterns of Juglans nigra. Juglans nigra had high economic, industrial and technological importance. It is cultivated for its wood, as a rootstock of Persian walnut trees, and for human consumption (nuts). In the standard germination test, and other seed's vigor tests, the results were expressed as percentage of normal seedlings. The objective of this work was to describe patterns of normal and abnormal seedlings of
\end{abstract}

1.- Cátedra de Cultivos Intensivos. Facultad de Ciencias Agrarias. Universidad Nacional de Rosario. C.C. 14. (S2125ZAA) Zavalla, provincia de Santa Fe. Argentina. Email: pflores@unr.edu.ar

2.- Cátedra de Cultivos Intensivos. Facultad de Ciencias Agrarias. Universidad Nacional del Litoral. Kreder 2805. (3080) Esperanza, provincia de Santa Fe. Argentina.

Manuscrito recibido el 26 de junio de 2018 y aceptado para su publicación el 2 de noviembre de 2018.

Flores, P.; Poggi, D.; García, S.; Catraro, M. \& Gariglio, N. Descripción de patrones normales y anormales de plántulas de Juglans nigra.

FAVE - Ciencias Agrarias 17 (2): 7-21. CC BY-NC-SA 4.0 (c) (i) (2) 
J. nigra to be used as references. The categories described were: Normal Vigorous (seedlings free of injuries), Normal Weak (seedlings with deficiencies or injuries) and Abnormal with defects at root and epicotile level.

Key words: Juglans nigra, normal seedlings, abnormal seedlings.

\section{INTRODUCCIÓN}

Juglans nigra L. pertenece al orden Juglandales, familia Juglandáceas, sección Rhysocaryon (35). También se lo denomina "Nogal negro del este”, es la planta más grande y la que posee la madera más valiosa de los nogales de Norteamérica. Además de cultivarse para la obtención de su madera, también se emplea como portainjerto de $J$. regia (17, 19, 25; 31). En Estados Unidos, su fruto es empleado en pastelería, panes, helados, ensaladas, caramelos y chocolates, constituyéndose en una especie de gran relevancia económica y con un elevado nivel industrial y tecnológico (21, 29, 31).

La germinación de las semillas de $J$. nigra es de tipo hipogea $(21,29,31)$. Sus plántulas se caracterizan por la presencia de cotiledones grandes y carnosos, que permanecen encerrados dentro del endocarpio leñoso por debajo de la superficie del suelo.

Cuando se inició el análisis de semillas, entre 1900 y 1920, todos los esfuerzos se concentraron en desarrollar procedimientos para comprobar la germinación de las semillas. Entretanto, algunos analistas ya habían observado diferencias significativas en la velocidad de la germinación y en el crecimiento de las plántulas entre lotes de la misma especie (16). Esas diferencias fueron atribuidas a la calidad fisiológica de las semillas denominada comúnmente como vigor de la semilla (10).
Cuando las semillas alcanzan su madurez fisiológica poseen el máximo vigor, pero luego este comienza a disminuir $(2,16)$. Esta pérdida de vigor se denomina deterioro y es consecuencia del proceso de envejecimiento de las semillas que en casos extremos culmina con la incapacidad de germinar (15). Otras consecuencias del proceso de deterioro son la disminución del porcentaje de plántulas normales, de la emergencia a campo bajo condiciones favorables, y de la velocidad y uniformidad del crecimiento de las plántulas, entre otras $(22,24,30)$.

En la Prueba de Germinación Estándar, y en las Pruebas de Crecimiento de Plántulas y de Envejecimiento Acelerado que se realizan para determinar vigor, los resultados se expresan en Porcentaje de Plántulas Normales (8,23, 24, 26, 28, 34), las cuales se caracterizan por estar libres de lesiones, tener todas las estructuras normales necesarias para el crecimiento y la capacidad para un desarrollo continuo. La Association Of Official Seed Analysts (AOSA) describe detalladamente las categorías de plántulas normales y anormales en términos generales (5) y al igual que la International Seed Testing Association (ISTA) (24) dentro de la categoría de plántulas normales especifica las deficiencias o irregularidades que pueden tolerarse. Esas deficiencias o defectos leves dan lugar a dos sub-categorías: normales vigorosas y normales débiles, distinguien- 
do así entre plántulas libres de defectos y plántulas con defectos admisibles, respectivamente. Algunas de esas irregularidades pueden contribuir a un menor vigor o calidad inferior, sin embargo, quedan ocultas en el porcentaje total de plántulas normales.

Entre estas deficiencias se puede mencionar la ausencia de raíz primaria, lesiones en el epicótile, ausencia de un cotiledón, necrosis en uno o ambos cotiledones y plántulas poco desarrolladas, entre otras (7).

Para determinar el número de plántulas normales de un modo preciso y confiable, es necesario que las pruebas se efectúen bajo un estricto rigor metodológico (25), lo que dependerá de la capacidad crítica del analista de laboratorio al momento de efectuar la evaluación (20). Siendo la evaluación de plántulas un punto crítico, las asociaciones de analistas $(7,24)$ y algunos investigadores han descripto patrones de plántulas de diferentes especies donde se detallan las características que deben reunir las mismas para ser consideradas plántulas normales (20).

En algunas especies están descriptas las plántulas normales y anormales como en Schinopsis balansae (3), Aspidosperma quebracho-blanco (4), algodón, frijoles, maní y soja (7). Mientras que para el caso de nogal negro ( $J$. nigra), como para Juglans regia, no se dispone de estas descripciones a nivel de plántulas.

Se define como Plántulas Anormales aquellas cuyos defectos son graves (24), tales como la ausencia de raíz primaria y raíces secundarias débiles, ausencia de epicótile, necrosis en epicótile, yema terminal dañada, ausencia de hipocótile, raíz retorcida, raíz con aspecto de tocón (mazuda o tipo stubby), raíz con geotropismo negativo, ausencia de los dos cotiledones o necrosis severas en ellos (7).
Para evaluar el vigor de las plántulas existen cuatro zonas claves donde realizar la evaluación morfológica: (1) el sistema radical, (2) el hipocótile, (3) los cotiledones, y (4) el epicótile. Durante la germinación, cada una de estas zonas debe estar esencialmente libre de defectos visuales $(7,25)$.

El objetivo de este trabajo fue describir patrones de plántulas normales y anormales de J. nigra como herramientas de gran utilidad para ser utilizadas en todas aquellas pruebas que expresan sus resultados en porcentaje de Plántulas Normales.

\section{MATERIAL Y METODOS}

Los frutos fueron cosechados a principios del mes de marzo, luego del llenado de la nuez y cuando el pericarpio comenzaba a oscurecerse produciéndose su dehiscencia parcial. Luego de cosechados los frutos se sumergieron en agua, y por maceración y lavado se les eliminó la pulpa (meso y exocarpio) (1). El conjunto constituido por la pepa y el endocarpio leñoso se desinfectó con hipoclorito de sodio al 2\% durante dos minutos (4) y se enjuagó abundantemente con agua destilada. Luego, se estratificaron en frío-húmedo envolviéndolos con papeles embebidos en agua e introduciéndolos en bolsas de polietileno negro para mantener la humedad. Las bolsas se colocaron en cámara a $5^{\circ} \mathrm{C}$ por un período de 4 meses (19).

Al finalizar el periodo de estratificación se realizó la Prueba de Germinación Estándar siguiendo las especificaciones de la ISTA (25). Los frutos se colocaron en bandejas de plástico sobre una capa de arena de $40 \mathrm{~mm}$ y se cubrieron con otros $20 \mathrm{~mm}$ de arena mojada y sin comprimir. 
Las bandejas se llevaron a una cámara de germinación (Forma Científico, Modelos 3744) durante 28 días con un régimen de temperaturas alternas de $20 / 30^{\circ} \mathrm{C}(16 \mathrm{~h} / 8 \mathrm{~h})$ a la luz $(11,18)$. Se utilizaron 4 repeticiones de 100 semillas cada una.

Al finalizar la Prueba de Germinación Estándar se procedió a la clasificación de las plántulas de Juglans nigra según el vigor, separando a las plántulas normales en dos categorías, las normales vigorosas (strong) y las normales débiles (weak). Se consideraron como plántulas normales vigorosas aquellas libres de lesiones, sin ningún tipo de deficiencia o anomalía, y como plántulas normales débiles aquellas que presentaron alguna deficiencia o anomalía leve y que aún así podían ser incluidas en la categoría de plántulas normales. Del mismo modo, se describieron plántulas anormales para esta especie.

Para realizar la clasificación se detallaron las características anatomo-morfológicas del sistema radical, cotiledones y epicó- tile, y debido a que en esta especie el hipocótile no es perceptible, no fue considerado como un factor de evaluación $(6,20)$. Se describieron las siguientes categorías de plántulas para la especie Juglans nigra:

I.- Normales Vigorosas (plántulas libres de lesiones).

II.- Normales Débiles (plántulas con deficiencias o lesiones).

III.- Anormales con defectos a nivel de raíz.

IV.- Anormales con defectos a nivel de raíz y epicótile.

V.- Anormales en cotiledones y sistema radical.

\section{RESULTADOS Y DISCUSIÓN}

Las plántulas normales vigorosas y normales débiles han sido descriptas a nivel del sistema radical y del sistema del vástago (Tabla 1).

Tabla 1: Descripción de Plántulas Normales de la especie Juglans nigra

\begin{tabular}{|c|c|}
\hline \multicolumn{2}{|r|}{ PLÁNTULAS NORMALES VIGOROSAS } \\
\hline Sistema radical & $\begin{array}{l}\text { Raíz primaria presente, sana, completa, extensa, buen desarrollo de raíces } \\
\text { secundarias (Fig. 1a). }\end{array}$ \\
\hline $\begin{array}{l}\text { Sistema del } \\
\text { vástago }\end{array}$ & $\begin{array}{l}\text { Estructura (epicótile) del tallo o vástago recto sin lesiones o necrosis, sano, } \\
\text { completo y con buen desarrollo. Hojas primarias sanas, hojas compuestas } \\
\text { normales (Fig. 1b). }\end{array}$ \\
\hline \multicolumn{2}{|r|}{$\begin{array}{l}\text { PLÁNTULAS NORMALES DÉBILES } \\
\text { (con anomalías o defectos aceptables) }\end{array}$} \\
\hline $\begin{array}{l}\text { Sistema radical y } \\
\text { sistema del } \\
\text { vástago }\end{array}$ & $\begin{array}{l}\text { Raíz primaria ausente, con raíces secundarias vigorosas, vástago recto, sin } \\
\text { malformaciones, hojas y yema terminal sana (Fig. } 2 \text { ). } \\
\text { Raíz primaria normal, raíces secundarias débiles. Talluelo con crecimiento } \\
\text { reducido, sin lesiones, yema terminal sana (Fig. } 3 \text { ). }\end{array}$ \\
\hline
\end{tabular}


Plántulas normales y anormales de J. Nigra
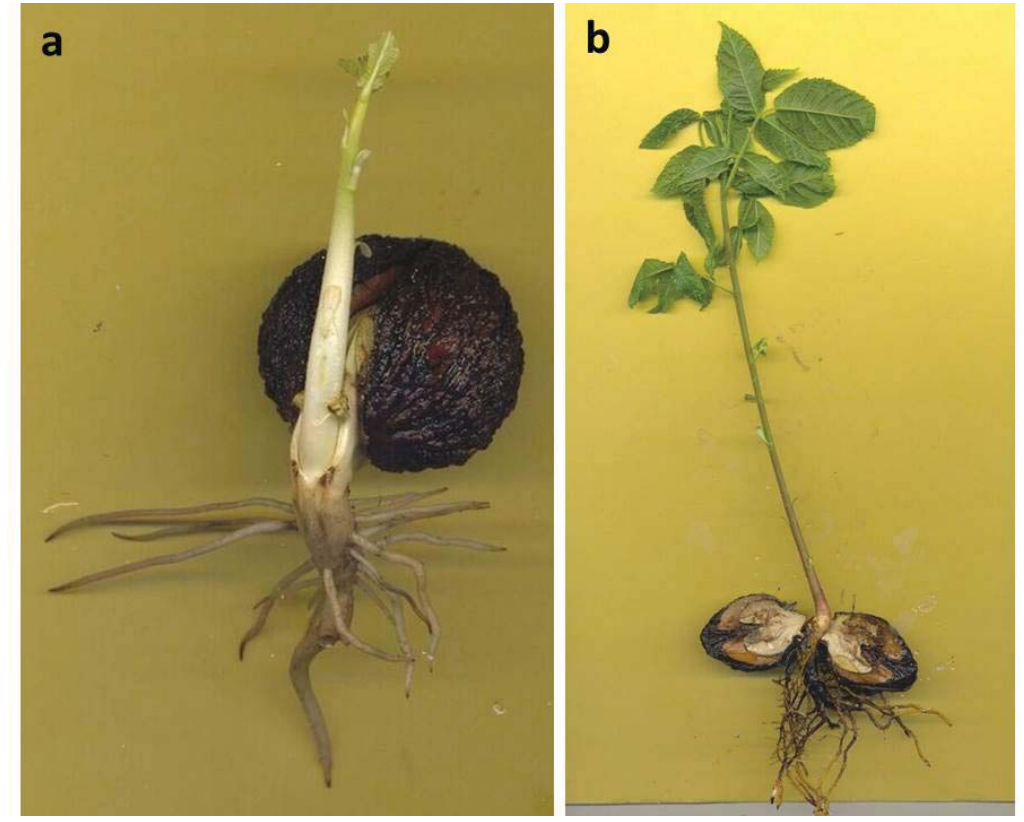

Fig. 1 a y b: Plántulas normales vigorosas.

Fig. 3: Plántula normal débil

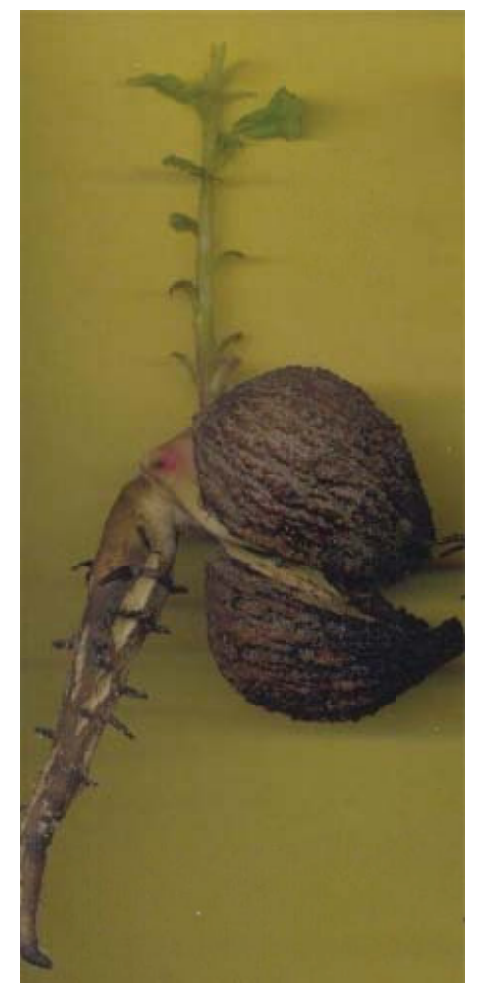

Revista FAVE - Ciencias Agrarias 17 (2) 2018 | 
P. Flores et al.

Se han descripto como plántulas tos o anomalías graves (Tabla 2). anormales aquellas que presentaron defec-

Tabla 2. Descripción de anormalidades graves de plántulas de la especie Juglans nigra

\begin{tabular}{|c|c|}
\hline \multicolumn{2}{|r|}{ ANORMALIDADES DEL SISTEMA RADICAL (Raíz primaria) } \\
\hline Mazuda & $\begin{array}{l}\text { Raíz corta, engrosada, atrofiada, con aspecto de tocón, denominada } \\
\text { comúnmente stubby. Ausencia de raíces secundarias (Fig. } 4 \text { a). }\end{array}$ \\
\hline Mazuda & Raíz tipo stubby y raíces secundarias sumamente débiles (Fig. 4b). \\
\hline $\begin{array}{l}\text { Con geotropismo } \\
\text { negativo }\end{array}$ & $\begin{array}{l}\text { Raíz con crecimiento anómalo hacia arriba, en contra de la fuerza de } \\
\text { gravedad (Fig. 5). }\end{array}$ \\
\hline $\begin{array}{l}\text { Mazuda con geotropismo } \\
\text { negativo }\end{array}$ & $\begin{array}{l}\text { Raíz tipo stubby, con crecimiento hacia arriba y raíces secundarias } \\
\text { vigorosas (Fig. 6a). }\end{array}$ \\
\hline Geotropismo negativo & Raíz primaria con desarrollo anormal, geotropismo negativo (Fig. 6b). \\
\hline Retorcida & Raíz que gira sobre si misma formando un rulo (Fig. 7). \\
\hline En banco & Raíz que no crece en forma recta (Fig. 8). \\
\hline \multicolumn{2}{|r|}{ ANORMALIDADES DEL SISTEMA RADICAL Y EPICÓTILE } \\
\hline $\begin{array}{l}\text { R. primaria ausente y } \\
\text { epicótile atrofiado }\end{array}$ & $\begin{array}{l}\text { Raíz primaria faltante, raíces secundarias ausentes, epicótile con falta de } \\
\text { desarrollo, y detención de su crecimiento (Fig. 9). }\end{array}$ \\
\hline $\begin{array}{l}\text { R. primaria ausente y } \\
\text { epicótile corto y grueso }\end{array}$ & $\begin{array}{l}\text { Raíz primaria faltante, raíces secundarias ausentes, epicótile con } \\
\text { disminución de su longitud, engrosado y con detención de su crecimiento } \\
\text { (Fig. 10). }\end{array}$ \\
\hline $\begin{array}{l}\text { R. primaria ausente y } \\
\text { yema terminal dañada }\end{array}$ & $\begin{array}{l}\text { Raíz primaria faltante, raíces secundarias con necrosis. La estructura de la } \\
\text { yema terminal se presenta lesionada o deteriorada (Fig. 11). }\end{array}$ \\
\hline $\begin{array}{l}\text { Raíz retrasada y yema } \\
\text { terminal dañada }\end{array}$ & $\begin{array}{l}\text { Raíz que no alcanza una longitud normal, con manifiesta necrosis y } \\
\text { estructura de la yema terminal lesionada (Fig. 12). }\end{array}$ \\
\hline $\begin{array}{l}\text { Raíz mazuda y yema } \\
\text { terminal dañada }\end{array}$ & $\begin{array}{l}\text { Raíz corta, engrosada, atrofiada, con aspecto de tocón, ausencia de } \\
\text { raíces secundarias. Necrosis en epicótile y cotiledones (Fig. 13). }\end{array}$ \\
\hline $\begin{array}{l}\text { Raíz retrasada y yema } \\
\text { terminal dañada }\end{array}$ & $\begin{array}{l}\text { Raíz que no alcanza una longitud normal, con raíces secundarias con } \\
\text { poco desarrollo. Elongación del epicótile con posterior necrosis de la yema } \\
\text { terminal (Fig. 14). }\end{array}$ \\
\hline $\begin{array}{l}\text { Raíz mazuda y yema } \\
\text { terminal perdida }\end{array}$ & $\begin{array}{l}\text { Raíz tipo stubby, raíces secundarias muy vigorosas. Detención del } \\
\text { crecimiento de la yema terminal con desarrollo de brotes axilares (doble } \\
\text { tallo) (Fig. 15). }\end{array}$ \\
\hline $\begin{array}{l}\text { Raíz mazuda y epicótile } \\
\text { detenido }\end{array}$ & $\begin{array}{l}\text { Raíz tipo stubby, raíces secundarias vigorosas. Estructura del tallo con } \\
\text { desarrollo normal y necrosis terminal (Fig. 16). }\end{array}$ \\
\hline \multicolumn{2}{|r|}{ ANORMALIDADES EN COTILEDONES Y SISTEMA RADICAL } \\
\hline Necróticos y raíz $n$ & $\begin{array}{l}\text { Los cotiledones presentan áreas con tejidos muertos y raíz tipo stubby } \\
\text { (Fig. 17). }\end{array}$ \\
\hline
\end{tabular}


Plántulas normales y anormales de J. Nigra

Fig. 5: Raíz primaria con geotropismo negativo.
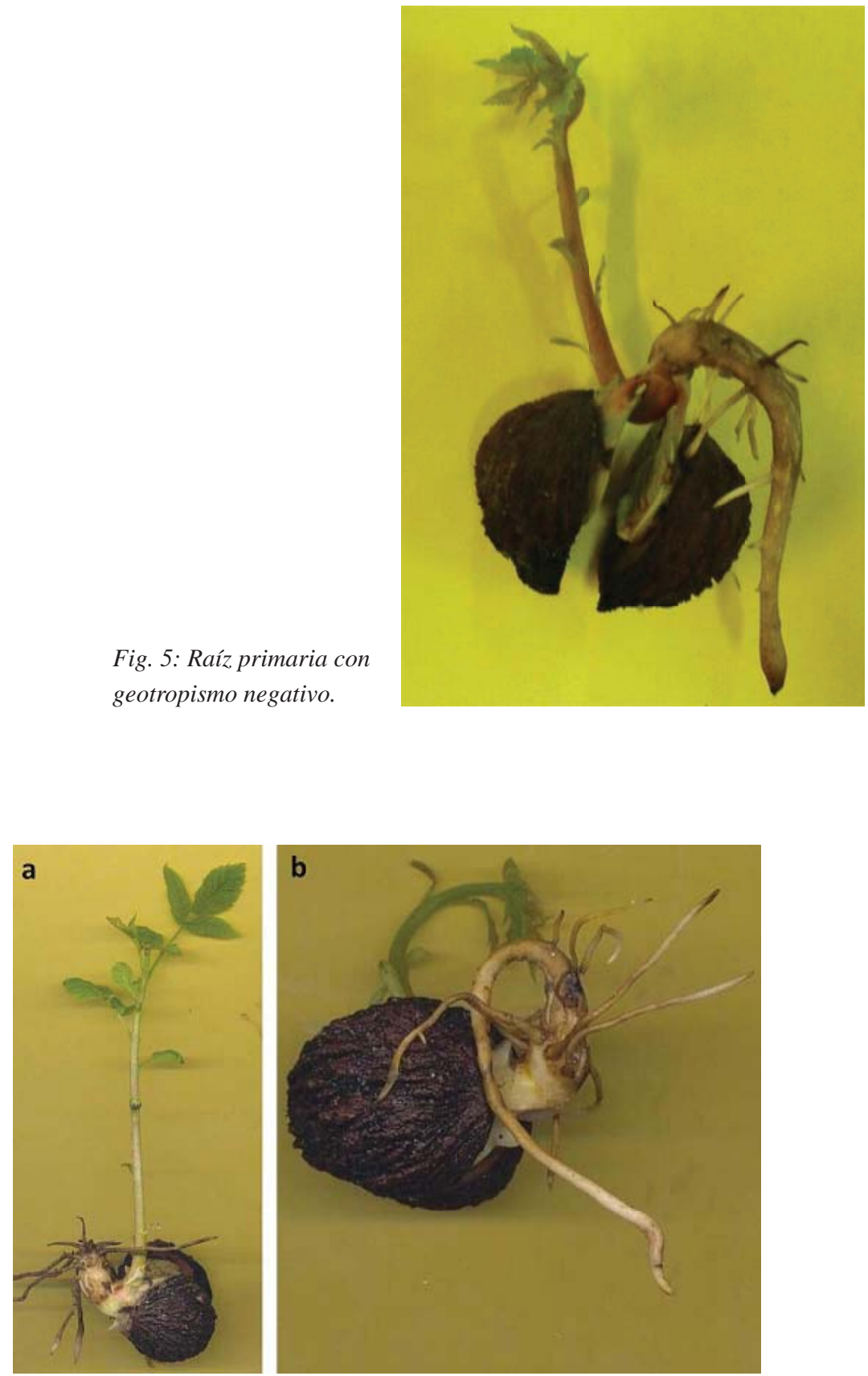

Fig. 6: Raíz mazuda (Stubby) con geotropismo negativo (Fig. 6a) y raíz con geotropismo negativo (Fig. 6b). 


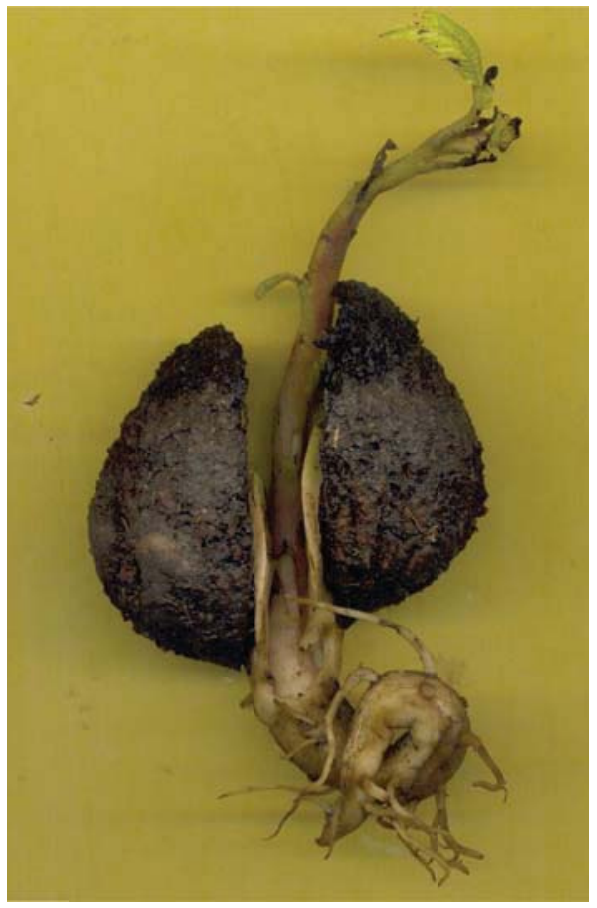

Fig. 7: Raíz retorcida.

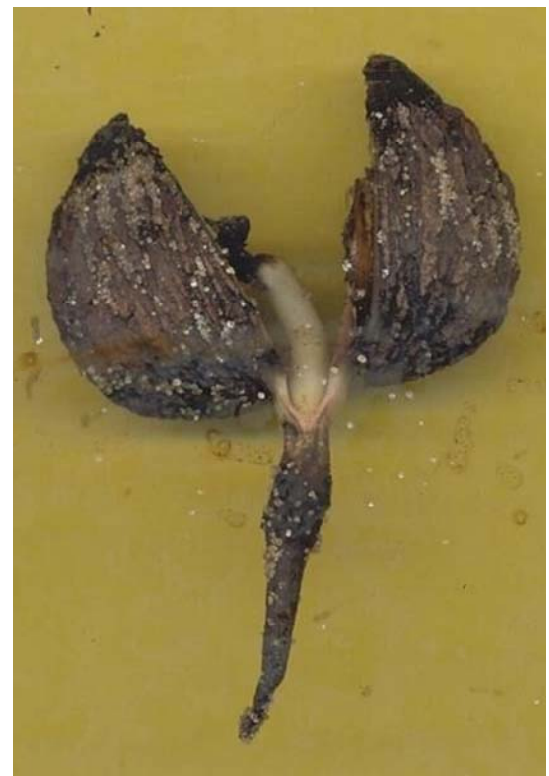

Fig. 12: Raíz retrasada y yema terminal dañada.

30

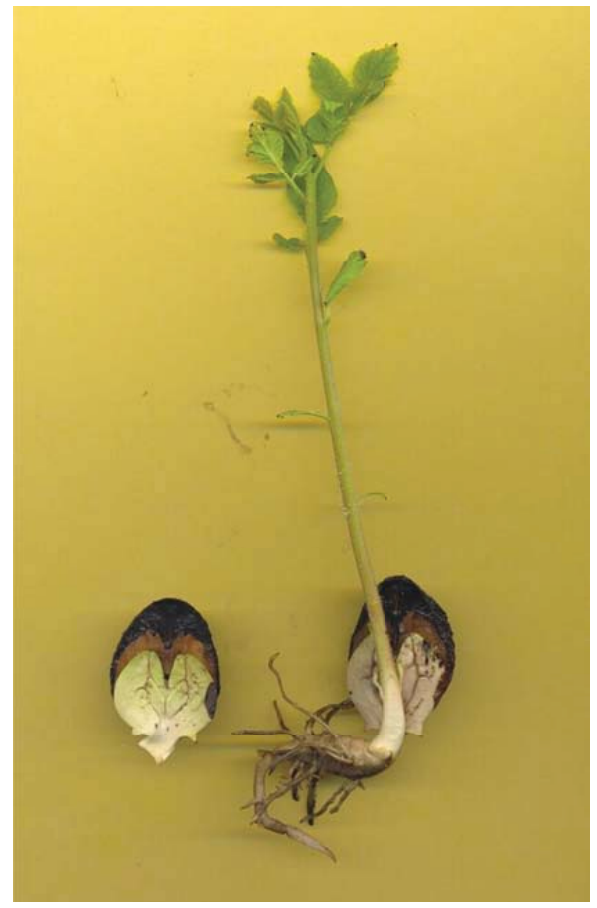

Fig. 8: Raíz en banco.

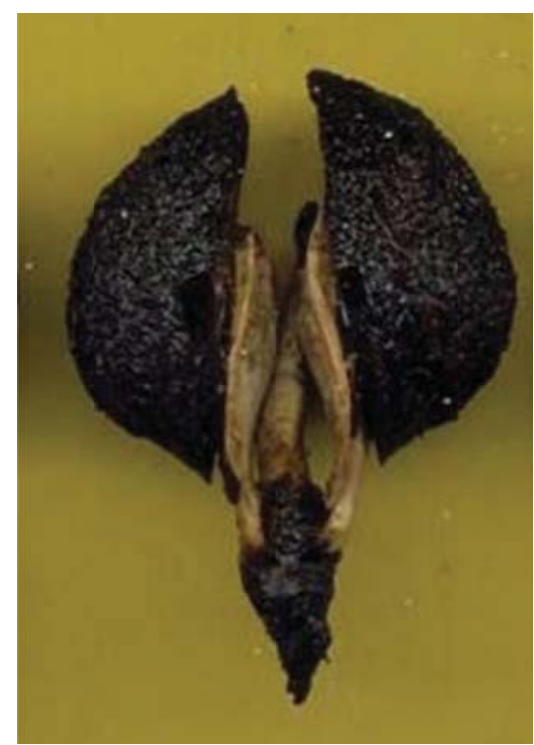

Fig. 13: Raíz mazuda ( Stubby) yema terminal dañada.

| Revista FAVE - Ciencias Agrarias 17 (2) 2018 


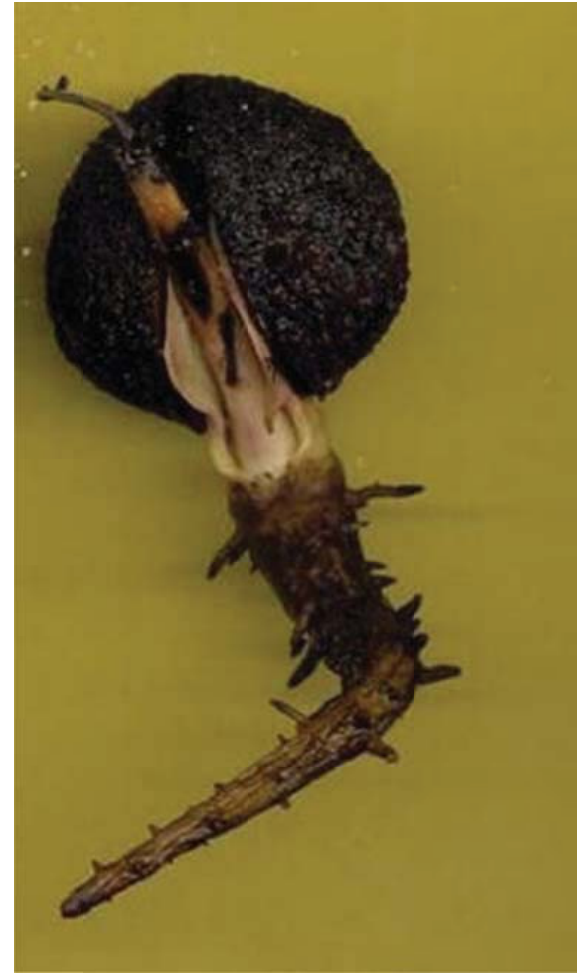

Fig. 14: Raíz retrasada y yema terminal dañada.

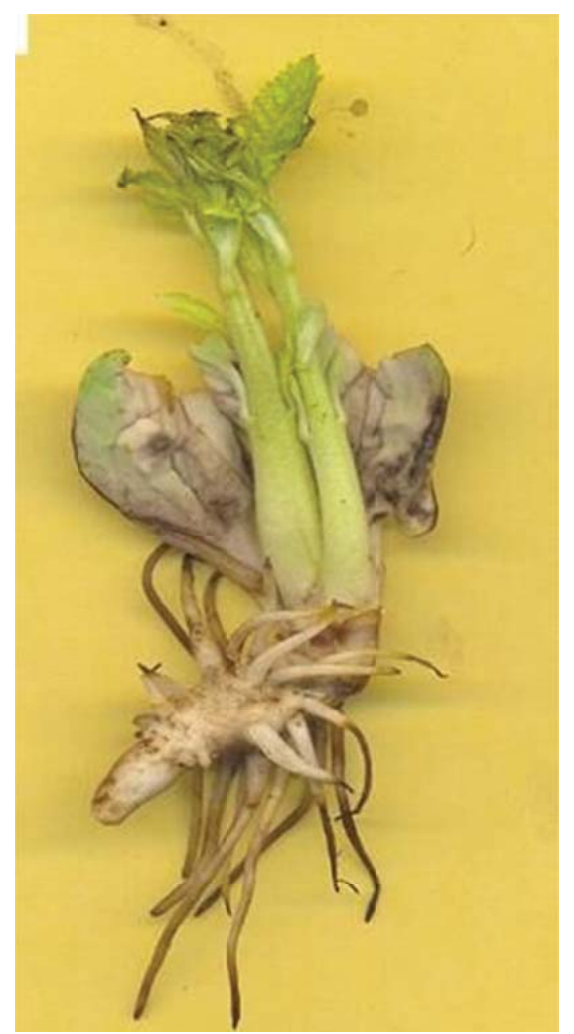

Fig. 15: Raíz mazuda y yema terminal perdida (doble tallo).
Tanto en la Prueba de Germinación Estándar, como en las pruebas de evaluación de germinación y crecimiento de plántulas, entre otras, es necesario contar con la descripción de plántulas que permitan expresar los resultados en porcentaje de plántulas normales $(7,8,9,20,33)$. Por otra parte, en las pruebas de vigor, como la Prueba de Envejecimiento Acelerado, además de los resultados de porcentaje de plántulas normales (24), también es necesario conocer el Peso Seco Radicular y el Peso Seco Aéreo, contabilizándose solamente el de las plántulas normales (28).

En especies como algodón, frijoles, maní, soja (7), quebracho colorado (3) y quebracho blanco (4), se dispone de éstas clasificaciones que constituyen herramientas útiles para los técnicos analistas cuando necesitan distinguir entre plántulas normales y anormales, y fundamentalmente entre las que pueden ser aceptadas como normales aún presentando alguna anomalía. Estas categorías no estaban descriptas para el nogal negro, por lo que los resultados de ésta investigación constituyen un avance importante en tal sentido.

Como J. nigra presenta germinación hipogea el hipocótile no es visible, por lo que se descarta como factor de evaluación morfológica (6). Por el contrario, en especies con germinación epigea la evaluación 
del hipocótile y de los cotiledones adquiere relevancia, como en el caso de lechuga (14), Prosopis nigra (12), y de Maytenus vitis-idaea (colquiyuyo); donde en esta última se consideran como normales incluso a las plántulas que poseen un solo cotiledón (13). En nuestra experiencia no se constataron casos de ausencia de uno o ambos cotiledones, solo se observó necrosis en menos del 50\% de los mismos (Fig. 17).

Entre los defectos graves que se observaron en el sistema radical de J. Nigra, y que determinaron que las plántulas sean consideradas anormales, se destacó el de raíz mazuda (tipo stubby), acompañada de raíces secundarias débiles, o sin raíces secundarias (Fig. 4a; Fig. 4b).

Esta anomalía también se ha observado en otras especies como en plántulas de algarrobo blanco, soja, algodón y maní (7,
33). Existen diferentes criterios para este patrón de raíz mazuda según la especie. Así, mientras en la familia Juglandaceae (Carya sp.) se consideran plántulas anormales (6), con esta misma anomalía se clasifica como plántulas normales débiles en Gossypium sp. (7). Según el ISTA, las plántulas que presenten raíz mazuda, pueden ser consideradas como normales siempre y cuando posean suficiente cantidad de raíces secundarias en óptimo estado sanitario y estructural $(7,20)$.

Otro defecto a nivel del sistema radical que se observó con frecuencia fue el de raíz primaria ausente y con ausencia de raíces secundarias (Fig. 9; Fig. 10), o con raíces secundarias con necrosis (Fig. 11), por lo que las plántulas deben ser registradas como anormales (7), al igual que lo descripto en Schinopsis balansae (3).

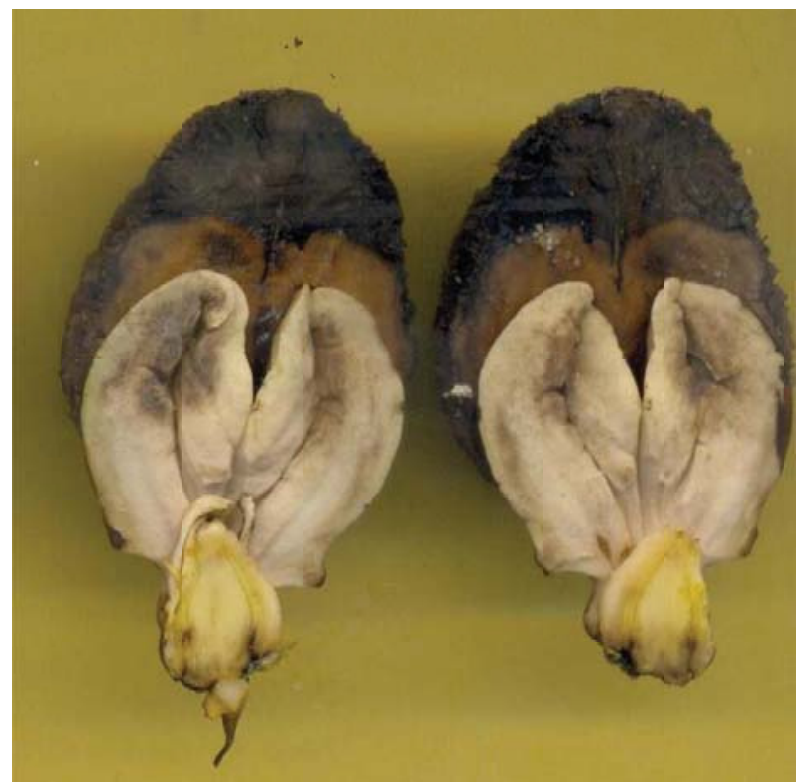

Fig. 17: Cotiledones necróticos y raíz mazuda. 
Plántulas normales y anormales de J. Nigra
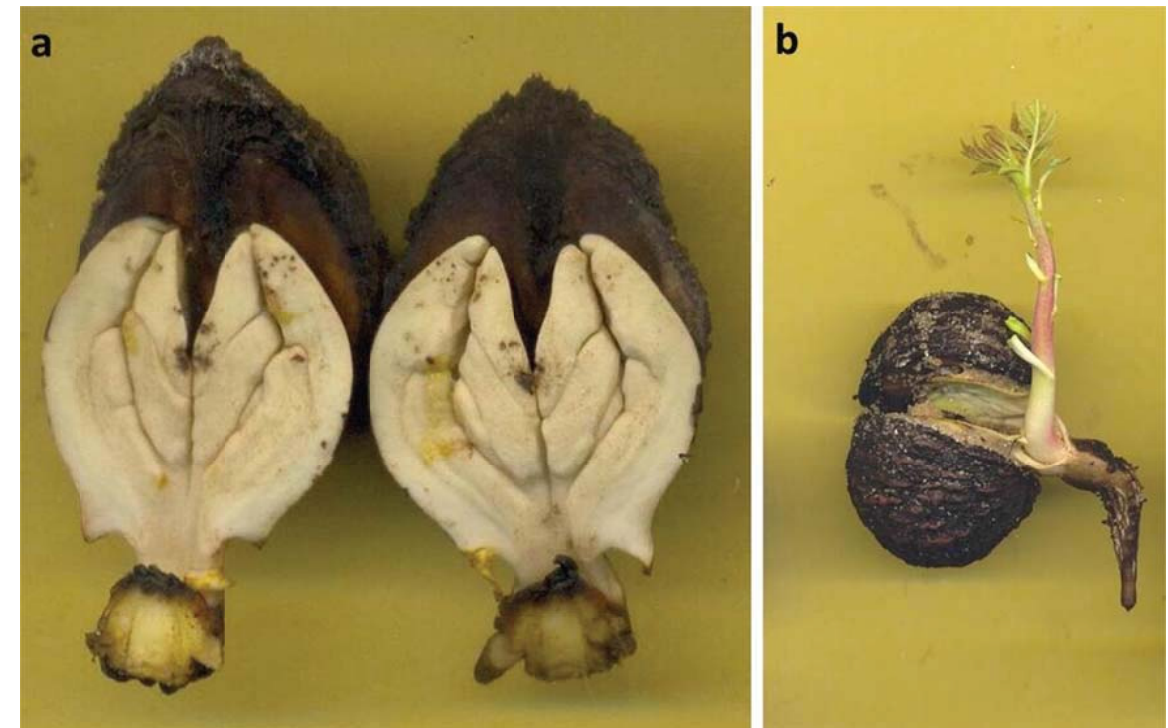

Fig. 4: Raíz mazuda (Stubby) con ausencia de raíces secundarias (a); raíz tipo stubby con raíces secundarias sumamente débiles (b).

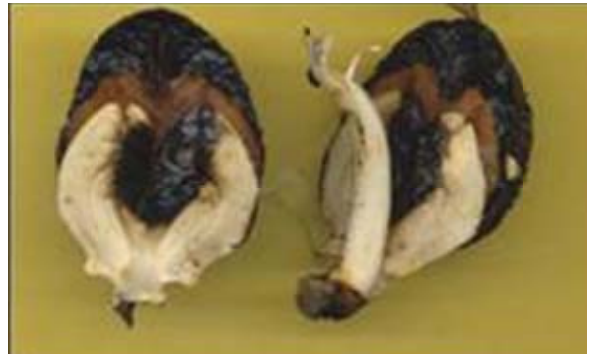

Fig. 9: Raíz primaria ausente y epicótile atrofiado.

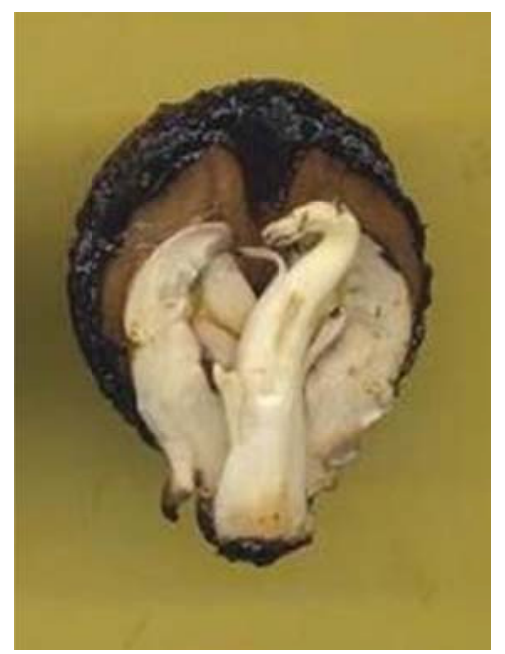

Fig. 10: Raíz primaria ausente y epicótile corto y grueso. 


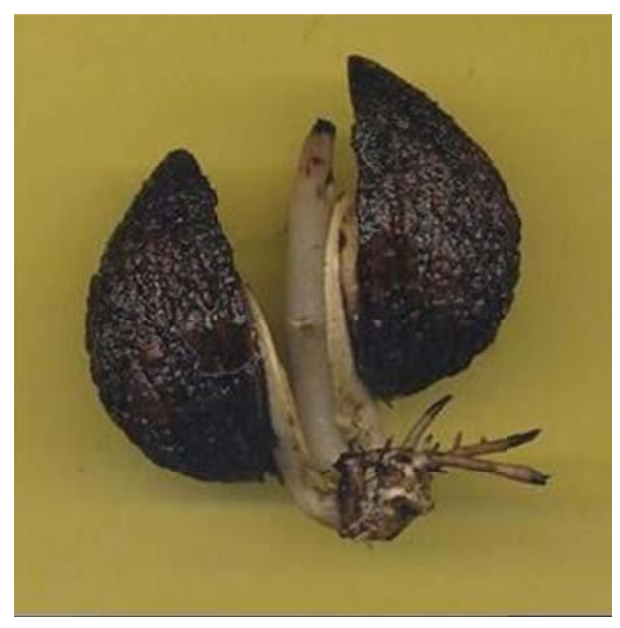

Fig. 11: Raíz primaria ausente y yema terminal dañada

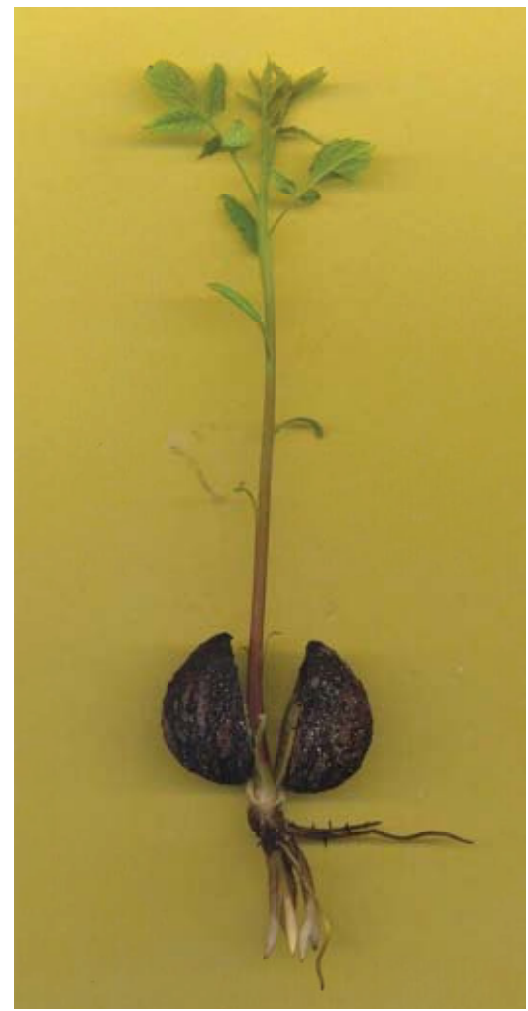

Fig. 2: Raíz primaria ausente, con raíces secundarias vigorosas, vástago recto, sin malformaciones, hojas y yema terminal sana.

Si bien en las diferentes pruebas los resultados se expresan como porcentaje de plántulas normales, es importante identificar y registrar aquellas plántulas conocidas como anormales, que son las que no muestran el potencial para continuar desarrollándose aun bajo condiciones óptimas. La identificación de las anormalidades constituye una herramienta valiosa para explicar la razón por la cual un lote de semillas presenta o no un bajo poder germinativo (20). nutrientes desde el suelo (20).

A nivel de la parte aérea lo más común fue observar plántulas con epicótile detenido y raíz mazuda (Fig. 16). 
Fig. 16: Raíz mazuda (Stubby) y epicótile detenido.

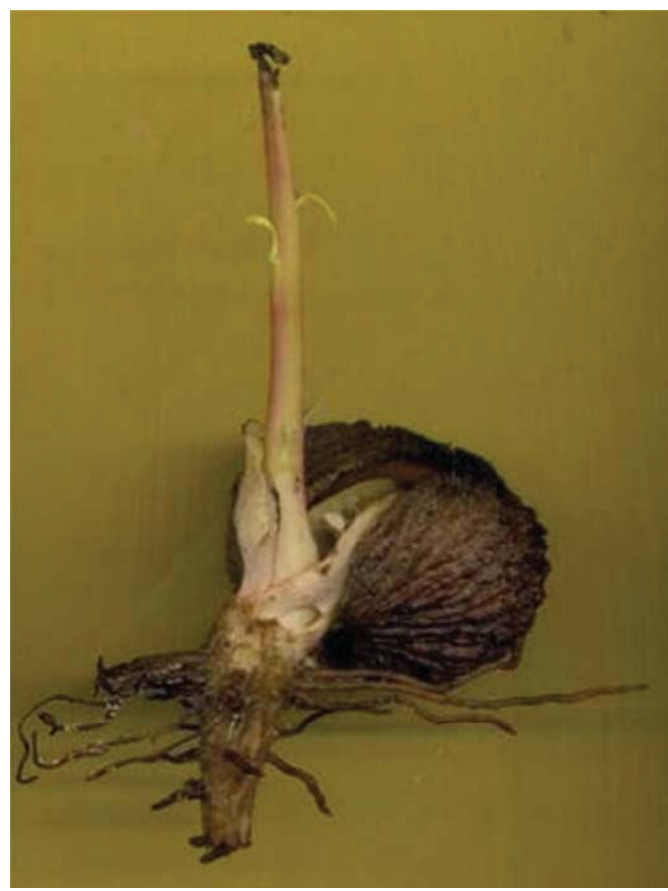

\section{CONCLUSIONES}

Se describieron veinte patrones de plántulas de las categorías plántulas normales vigorosas, plántulas normales débiles y plántulas anormales. Estos patrones serán de gran utilidad en el momento de expresar los resultados en las diferentes pruebas de análisis de semillas del nogal negro.

La anormalidad más común observada fue raíz mazuda (tipo stubby) con raíces secundarias débiles, o sin raíces secundarias, y como plántula normal débil lo más visto fue raíz primaria ausente con raíces secundarias vigorosas, vástago vigoroso, sin lesiones y con yema terminal sana.

\section{BIBLIOGRAFÍA}

1.- ALDHOUS, J.R. 1972: Nursery practice. Forestry Comm. Bull. $N^{\circ} 43$, Londres.

2.- ALIZAgA, R., MELLO VERA, D. C., DOS SANTOS, D. S. B. y LRIGON, D. 1994. Evaluación del vigor en semilla de Phaseolus vulgaris y su relación con la emergencia en el campo. Agronomía Costarricense 18(2): 227-234.

3.- ALZUGARAY, C., CARNEVALE, N., SALINAS, A. y PIOLI, R. 2005. Observations on quality of Schinopsis balansae Engl. seeds. Seed Technology 27: 49-58.

4.- ALZUGARAY, C., CARNEVALE, N., SALINAS, A. y PIOLI, R. 2006. Calidad de semillas de Aspidosperma quebracho-blanco Schlecht. Quebracho 13: 26-35.

5.- AOSA (Association of Official Seed Analysts). 1978. Rules for testing seeds. J. Seed Technol. 3(3): 1-126. 
6.- AOSA (Association of Official Seed Analysts). 1992. Seedling Evaluation Handbook. Contribution No 35. 101 p.

7.- AOSA (Association of Official Seed Analysts). 2002. Seed Vigor Testing Handbook. Contribution $\mathrm{N}^{\circ}$ 32. Revised 2002. $105 \mathrm{p}$.

8.- BARONE, J., DUARTE, E. y LUNA, C. 2016. Determinación de la eficacia de métodos de evaluación de calidad de semillas de especies forestales nativas de la Selva Atlántica. Quebracho 24(1, 2): 70-80.

9.- BENNETT, M. 2002. Saturated salt accelerated aging (SSAA) and other vigor tests for vegetable seeds. In: Proceedings International Seed Seminar: Trade, Production and Technology. Ed. McDonald, M.; Contreras, S. Pontificia Universidad Católica de Chile, Facultad de Agronomía e Ingeniería Forestal, Departamento de Ciencias Vegetales. Santiago- Chile. 188-193.

10.- BONNER, F. T., VOZZO J.A., ELAM W. W. y LAND, S.B. JR. 1994. Tree Seed Technology Training Course. Instructor's Manual. USDA, Forest Service. New Orleans, Louisiana. 160 p.

11.- BRINKMAN, K.A. 1974. Juglans L. In: Seeds of Woody Plants (coord. C. S. Schopmeyer), 454459. USDA-FS, AH, Washington, DC.

12.- CARNEVALE, N. J., ALZUGARAY, C. y LÓPEZ, D. 2004. Efecto de la salinidad sobre el establecimiento de plántulas de dos especies arbóreas dominantes en un quebrachal de Schinopsis balansae ENGL. (Argentina). Revista de Investigaciones de la Facultad de Ciencias Agrarias - UNR. 6: 43-49.

13.- CARNEVALE, N. J., ALZUGARAY, C. y SALINAS, A. R. 2011. Quality and Germination of Maytenus vitis-idaea Seeds. Seed Technology Journal. 33 (1):29-39.

14.- CONTRERAS, S. y BARROS, M. 2005. Pruebas de Vigor en Semillas de Lechuga y su Correlación con Emergencia. Cien. Inv. Agr. 32 (1): 3-11.
15.- DELOUCHE, J. C. 1976. Germinación, Deterioro y Vigor de semillas. Seed News, Mississippi State Universtity. 16.- DELOUCHE, J. C. 2002. Germinación, deterioro y vigor de semillas. Seeds News 6 (6).

17.- DIRR, M.A. 1998. Manual of woody landscape plants: their identification, ornamental characteristics, culture, propagation and uses, 5th edn. Stipes Publishing, Champaign, 500-502 pp.

18.- ELLIS, R. H., HONG T. D., ROBERTS, E. H. 1985. Handbook of Seed Technology for Genebanks. Volume II. Juglandaceae. International Board for Plant Genetic Resources, Rome, Italy.

19.- FLORES, P., POGGI, D., GARCÍA, S., CATRARO, M. y GARIGLIO, N. 2017. Ruptura de la dormición y exigencias de luz para la germinación de semillas de Juglans nigra. FAVE, Ciencias Agrarias 16 (2): 1-46.

20.- GALLO, C., CRAVIOTTO, R. y ARANGO, M. 2013. Resultados confiables de germinación: la importancia de la evaluación de las plántulas de soja. Análisis de semillas. 27: 43-49.

21.- HAMMONS, B. K. 1998. "World Consumption and Production Trends". Published by International Nut Council. Hammons Products Company. 25-28.

22.- HAMPTON, J. G. y TEKRONY, D. M. 1995. Handbook of vigour test methods. 3 ed. Zurich, Suiza. The International Seed Testing Association. 117 p.

23.- ISTA (International Seed Testing Association). 1993. Supplement to Seed Science and Technology Zurich. 288 p.

24.- ISTA (International Seed Testing Association). 1995. Handbook of vigor test methods. 3. ed. Zurich. 117 p.

25.- ISTA (International Seed Testing Association). 2003. International rules for seed testing. Zurich, 333 p. 
26.- MARCOS FILHO J., NOVEMBRE, A. 31- ROSENGARTEN, F. Jr. 2004. The book D. y CHAMMA, H. M. 2001. Testes de of edible nut. Dover Publication, Inc. Mineoenvelhecimiento acelerado e de deterioraçâo controlada para avaliaçâo do vigor de sementes de soja. Scientia Agrícola, 58: 421-426.

27.- MCGRANAHAN, G. H. y CATLIN P. B. 1987. Juglans rootstocks. In: Rom R. C.; Carlson, R. F. (Eds.). Juglans rootstocks for fruit crops. 411-450. NY, Wiley.

28.- MURCIA, M., DEL LONGO, O., ARGÜELLO, J., PÉREZ, M. y PERETTI, A. 2006. Evaluación del crecimiento de plántulas de cultivares de girasol con diferentes proporciones de ácidos oleico/linoleico en respuesta a la baja temperatura. Rev. bras. Sementes. 28 (2) Pelotas. Brasil.

29.- REID, W., COGGESHALL, M. y GARRETT, G. 2007. Growing Black Walnut for Nut Production. Agroforestry in action. (ed). The University of Missouri Center for Agroforestry. $16 \mathrm{p}$. la, New York. 239-264.

32.- SOTOLONGO SOSPEDRA, R., GEADA LÓPEZ, G. y COBAS LÓPEZ, M. 2010. Fomento Forestal. Félix Varela. La Habana. Cuba. 287 p.

33.- SPOLJARIC, M. V. y OJEDA, A. D. 2009. Evaluación de parámetros de calidad en semillas de Prosopis alba Griseb leguminosa almacenadas en cámara de frío del banco de germoplasma del INTA Sáenz Peña. Publicación INTA Centro Regional Chaco Formosa. Estación Experimental Agropecuaria Saenz Peña.14 p.

34.- TEKRONY, D. M. 1995. Accelerated ageing. In: Congress Of The International Seed Testing Association, Copenhagen. Seed vigour testing: contributions to a seminar. Zurich: International Seed Testing Association. 816-822.

30.- ROMANO, A., TEVES, I., TORRES, N. 35.- WOODWORTH, R. H. 1930. Meiosis of y CAZÓN, L. 2008. Variaciones en la calidad de semillas de poroto (Phaseolus vulgaris l.) por efectos del daño mecánico y su inmicrosporogenesis in the Juglandaceae. Am. J. Bot 17(9): 863-869. 26 (2): 83-87. 